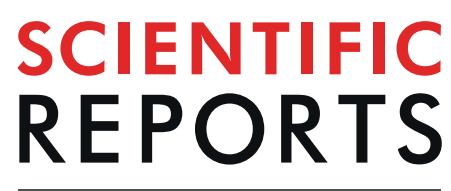

natureresearch

\title{
Glycemic control and use of glucose-lowering medications in hospital-admitted type 2 diabetes patients over 80 years
}

\author{
Ditte Resendal Gotfredsen ${ }^{1}$, Siri Vinther ${ }^{1}$, Tonny Studsgaard Petersen ${ }^{1,2}$, Rikke Cortes ${ }^{1}$, \\ Thomas Bo Jensen $(1)^{1,2}$, Espen Jimenez-Solem ${ }^{1,2}$ \& Mikkel Bring Christensen ${ }^{1,2,3 *}$
}

Treatment guidelines for type 2 diabetes (T2D) recommend avoidance of hypoglycemia and less stringent glycemic control in older patients. We examined the relation of glycemic control to glucoselowering medications use in a cohort of patients aged $>80$ years with a diagnosis of T2D and a hospital admission in the Capital Region of Denmark in 2012-2016. We extracted data on medication use, diagnoses, and biochemistry from the hospitals' records. We identified 5,172 T2D patients with high degree of co-morbidity and where $17 \%$ had an $\mathrm{HbA}_{1 \mathrm{c}}$ in the range recommended for frail, comorbid, older patients with type 2 diabetes $(58-75 \mathrm{mmol} / \mathrm{mol}(7.5-9 \%)$ ). Half of the patients $(n=2,575)$ had an $\mathrm{HbA}_{1 \mathrm{c}}<48 \mathrm{mmol} / \mathrm{mol}(<6.5 \%)$, and a majority of these ( $36 \%$ of all patients) did not meet the diagnostic criteria for T2D. Of patients treated with one or more glucose-lowering medications $(n=1,758)$, $20 \%$ had $\mathrm{HbA}_{1 \mathrm{c}}$-values $<42 \mathrm{mmol} / \mathrm{mol}(<6 \%)$, and $1 \%$ had critically low $\mathrm{Hba}_{1 \mathrm{c}}$ values $<30 \mathrm{mmol} / \mathrm{mol}$ $(<4.9 \%)$, In conclusion, among these hospitalized T2D patients, few had an $\mathrm{HbA}_{1 \mathrm{c}}$ within the generally recommended glycemic targets. One third of patients did not meet the diagnostic criteria forT2D, and of the patients who were treated with glucose-lowering medications, one-fifth had $\mathrm{HbA}_{1 \mathrm{c}}$-values suggesting overtreatment.

For patients with type 2 diabetes, it is important to maintain blood glucose levels as close to normal as possible in order to reduce the risk of micro- and macrovascular complications ${ }^{1-4}$. Treatment should, however, be individualized according to comorbidities, disease duration, risk of adverse events and in particular hypoglycemia, life expectancy as well as the patient's own preferences, resources and support system ${ }^{1}$. Elderly people with type 2 diabetes will generally have co-existing illness and relatively few resources ${ }^{5}$. Life expectancy will often be shorter than the time it takes for micro- and macrovascular disease complications to develop and manifest ${ }^{6,7}$. This is in contrast to the potential adverse effects of glucose-lowering medications that often appear in the short term. Hypoglycemia is the most important example of an acute and potentially fatal adverse effect to which elderly are particularly vulnerable ${ }^{8-15}$. Less effective counterregulatory mechanisms, decreased drug elimination, motor and cognitive impairment as well as unspecific/uncharacteristic symptoms all contribute to the heightened risk in elderly patients ${ }^{16}$. Thus, the overall goal with treatment individualization should be to weigh the typically long-term benefits vs. therapy burden and risk of adverse events on the shorter term ${ }^{7,15,17,18}$. Available evidence from the few clinical trials enrolling elderly patients with type 2 diabetes support that the benefits of intensive glycemic control targeting near-normal glycemia may not outweigh potential risks in this population ${ }^{8,19-22}$. This is also reflected in several international guidelines which generally advocate a less stringent treatment approach for older people with coexisting illnesses. An $\mathrm{HbA}_{1 \mathrm{c}}$ target of $58-75 \mathrm{mmol} / \mathrm{mol}$ (7.5-9\%) after pharmacological intervention, is generally recommended ${ }^{1,6,7,17}$. Recent studies have, however, questioned the extent to which these recommendations have been adopted and implemented in clinical practice ${ }^{12,23,24}$.

Previous studies examining trends in use, effects (glycemic control as measured by $\mathrm{HbA}_{1 \mathrm{c}}$ ) and harms (e.g. hypoglycemia) of glucose-lowering medications have predominantly focused on the general type 2 diabetes population $^{25-31}$. This study focuses on a cohort of patients aged 80 years or older with a diagnosis of type 2 diabetes

${ }^{1}$ Department of Clinical Pharmacology, Bispebjerg and Frederiksberg Hospital, Copenhagen, Denmark. ${ }^{2}$ Department of Clinical Medicine, University of Copenhagen, Copenhagen, Denmark. ${ }^{3}$ Center for Clinical Metabolic Research, Gentofte Hospital, University of Copenhagen, Hellerup, Denmark. *email: Mikkel.bring.christensen@regionh.dk 
and a hospital-based health record in the period 2012-2016. The main objective was to examine glycemic control in relation to use of glucose-lowering medications; secondary objectives included characterizing the patient cohort with regards to comorbidity, drug administration and biochemical status at the time of hospital admission.

\section{Results}

Patient characteristics and admission diagnoses. A total of 5,172 patients with type 2 diabetes were included in the study (Table 1). The median age was 84 years (IQR $82-88$ years) and $54 \%$ of the patients were female. Based on Body Mass Index (BMI), $41 \%$ were normal weight (BMI $18.5-25 \mathrm{~kg} / \mathrm{m}^{2}$ ) and $55 \%$ were overweight or obese (BMI $>25 \mathrm{~kg} / \mathrm{m}^{2}$ ) (Table 1). Regarding biochemical status, LDL-cholesterol was $>2,5 \mathrm{mmol} / \mathrm{L}$ for $25 \%$ of the patients. The estimated glomerular filtration rate (eGFR) was $\leq 60 \mathrm{mmol} / \mathrm{L}$ for $57 \%$ of the patients and $56 \%$ had a hemoglobin below the reference level calculated for men and women respectively (Table 1). The median duration of hospital admission was four days with pneumonia being the most common cause of admission $(4 \%, n=211)$. Diabetes related diagnoses were registered as the primary cause of admission for $2 \%(n=78)$ of all patients and $1 \%(\mathrm{n}=70)$ had hypoglycemia as the primary cause of admission.

Comorbidities. The majority $(82 \%, \mathrm{n}=4,228)$ of patients had a high level of comorbidity with a value $>2$ on the Charlson Comorbidity Index (Table 1). Detailed data on the cognitive status of the patients was not available, but $16 \%$ had a diagnosis of dementia (Table 2). Hypertension was the most commonly registered comorbidity (71\%), followed by congestive heart failure (32\%), peripheral vascular disease (18\%) and previous myocardial infarction (13\%) (Table 2).

Glycemic control. The distribution of HbAlc values is shown in Fig. 1. Most patients $(91 \%, \mathrm{n}=4,710)$ had an $\mathrm{HbA}_{1 \mathrm{c}}$ between 30-75 mmol/mol (4.9-9\%). Half of the patients $(\mathrm{n}=2,575)$ had an $\mathrm{HbA}_{1 \mathrm{c}}<48 \mathrm{mmol} / \mathrm{mol}(<6.5 \%)$, and $26 \%(\mathrm{n}=1,361)$ had an $\mathrm{HbA}_{1 \mathrm{c}}<42 \mathrm{mmol} / \mathrm{mol}(<6 \%)$. In the other end of the spectrum, $8 \%(\mathrm{n}=405)$ had $\mathrm{HbA}_{1 \mathrm{c}}$-values $>75 \mathrm{mmol} / \mathrm{mol}(>9 \%)$ (Table 1$)$. A total of $17 \%(\mathrm{n}=891) \mathrm{had}$ an $\mathrm{HbA}_{1 \mathrm{c}}$ between $58-75 \mathrm{mmol} / \mathrm{mol}$ (7.5-9\%), i.e. within the interval recommended for elderly, comorbid patients with overt type 2 diabetes (Table 1).

Glucose-lowering medications. Close to one third of patients $(34 \%, \mathrm{n}=1,758)$ were treated with at least one glucose-lowering medication at discharge (Table 3); $41 \%(\mathrm{n}=2,100)$ were administered at least one glucose-lowering medication, including sliding scale bolus insulin, during the index hospital admission (data not shown). Among the patients treated with glucose-lowering medication at discharge, one fourth (25\%, $\mathrm{n}=448$ ) were treated with two or more glucose-lowering medications (Table 3 ). The most commonly used glucose-lowering medications were metformin (50\%), basal insulin (32\%), bolus insulin (10\%), sulphonylureas (14\%) and dipeptidyl peptidase-4 inhibitors (14\%) (Table 4).

Glucose-lowering medications in relation to glycemic control. Of those treated with a glucose-lowering medication at discharge $(\mathrm{n}=1,758)$, close to half $48 \%, \mathrm{n}=844)$ had an $\mathrm{HbA}_{1 \mathrm{c}}$ within the interval recommended for elderly without significant comorbidity (43-57 mmol $/ \mathrm{mol}(6.0-7.5 \%)$ ). One third had higher HbAlc-values, $21 \%(\mathrm{n}=374)$ had a Hbalc between $58-74 \mathrm{mmol} / \mathrm{mol}(7.5-9)$, and $10 \%(\mathrm{n}=182)$ had $\mathrm{Hbalc}>75 \mathrm{mmol} / \mathrm{mol}(9 \%)$; while the remaining $20 \%(\mathrm{n}=343)$ had near-normalized $\mathrm{Hba} \mathrm{c}(<42 \mathrm{mmol} / \mathrm{mol}$ $(6 \%))$ while continuing glucose-lowering medication at discharge. Of the patients with near-normalization of Hbalc values, $15 \%(n=52)$ took two or more glucose-lowering medications (Table 3, Fig. 1) most frequently metformin, insulin and sulphonylureas (Table 4$)$. One percent $(\mathrm{n}=15)$ of the patients treated with an glucose-lowering medication at discharge had very low $\mathrm{Hba}_{1 \mathrm{c}}$-values $<30 \mathrm{mmol} / \mathrm{mol}(<4.9 \%)$ (Table 3, Fig. 1).

For those patients who did not receive a glucose-lowering medication at discharge $(\mathrm{n}=3,414), 55 \%(\mathrm{n}=$ $1,865)$ had $\mathrm{HbA}_{1 \mathrm{c}}$-values that did not justify a diagnosis of type 2 diabetes (i.e. $\mathrm{HbA}_{1 \mathrm{c}}<48 \mathrm{mmol} / \mathrm{mol}(<6,5 \%)$ ) (Table 3, Fig. 1). At the other end of the spectrum, $7 \%(n=223)$ had Hbalc levels for which glucose-lowering medications are generally recommended (i.e. $>75 \mathrm{mmol} / \mathrm{mol}(9 \%)$ ).

\section{Discussion}

Based on hospital electronic health records covering the entire population of the Capital Region of Denmark (1.8 million inhabitants) from 2012 to 2016, we investigated the demographics and the degree of glycemic control in relation to glucose-lowering medications in patients with type 2 diabetes aged 80 years or more. Our main findings were (1) almost half of the patients had an $\mathrm{HbA}_{1 \mathrm{c}}<48 \mathrm{mmol} / \mathrm{mol}(<6,5 \%)$, and of these $72 \%(\mathrm{n}=1865$, $36 \%$ of all patients) were not treated with a glucose-lowering medication and thus did not fulfil the diagnostic criteria of type 2 diabetes; (2) of the patients treated with one or more glucose-lowering medications (often including insulin and/or sulphonylureas), $20 \%$ had $\mathrm{HbA}_{1 \mathrm{c}}$-values below $42 \mathrm{mmol} / \mathrm{mol}(6 \%)$ and $1 \%$ had critically low $\mathrm{HbA}_{1 \mathrm{c}}$ values $<30 \mathrm{mmol} / \mathrm{mol}(<4.9 \%)$, indicating overtreatment. Conversely, $8 \%$ of all patients had Hba1c values $>75 \mathrm{mmol} / \mathrm{mol}(>9 \%)$, indicating possible undertreatment.

A surprising finding was that based on $\mathrm{HbA}_{1 \mathrm{c}}$-value, $36 \%(\mathrm{n}=1,865)$ of all the admitted patients did meet the criteria for their diagnosis of type 2 diabetes. The diagnoses were all registered by a physician authorized in Denmark and could have been registered many years prior to the index admission. Thus, one potential explanation for our finding could be that type 2 diabetes is not a chronic disease but rather a condition that may in some cases remit with old age - a notion that has been proposed before ${ }^{32,33}$. Hence, Abdelhafiz et al. proposed that frailty among older people with type 2 diabetes might lead to the remission of type 2 diabetes with the suggested mechanisms being weight loss accompanied by reduced amounts of visceral fat and thereby improved insulin sensitivity ${ }^{32}$. Such a mechanism bears resemblance to that described for patients having bariatric surgery and/or substantial weight loss and afterwards experience remission of their type 2 diabetes $^{34,35}$. 


\begin{tabular}{|c|c|}
\hline & n (\%) \\
\hline Unique patients, number & $5172(100 \%)$ \\
\hline \multicolumn{2}{|l|}{ Gender } \\
\hline Male & $2392(46 \%)$ \\
\hline Female & $2780(54 \%)$ \\
\hline Age in years (median, IQR) & $84(81.5-87.6)$ \\
\hline Days of admission (median, IQR) & $4(1-9)$ \\
\hline \multicolumn{2}{|l|}{ BMI $(n=4139)$} \\
\hline$<18.5$ & $163(4 \%)$ \\
\hline $18.5-<25$ & $1685(41 \%)$ \\
\hline $25-<30$ & $1454(35 \%)$ \\
\hline $30-<40$ & $766(19 \%)$ \\
\hline$\geq 40$ & $71(2 \%)$ \\
\hline \multicolumn{2}{|l|}{ Charlson Comorbidity Index } \\
\hline 0 & $0(0 \%)$ \\
\hline 1 & $342(7 \%)$ \\
\hline 2 & $602(12 \%)$ \\
\hline$>2$ & $4228(82 \%)$ \\
\hline \multicolumn{2}{|l|}{$\mathrm{HbA}_{\mathrm{lc}}(\mathrm{mmol} / \mathrm{mol})$} \\
\hline$<30$ & $57(1 \%)$ \\
\hline $30-41$ & $1304(25 \%)$ \\
\hline $42-47$ & $1214(23 \%)$ \\
\hline $48-52$ & $757(15 \%)$ \\
\hline $53-57$ & $544(11 \%)$ \\
\hline $58-74$ & $891(17 \%)$ \\
\hline$\geq 75$ & $405(8 \%)$ \\
\hline $\mathrm{LDL}(\mathrm{mmol} / \mathrm{L})$ & $(n=2983)$ \\
\hline$<1.8$ & $1379(46 \%)$ \\
\hline $1.8-2.5$ & $856(29 \%)$ \\
\hline$>2.5$ & $748(25 \%)$ \\
\hline Total cholesterol (mmol/L) & $(\mathrm{n}=2222)$ \\
\hline$<5$ & $1820(82 \%)$ \\
\hline$\geq 5$ & $402(18 \%)$ \\
\hline HDL (mmol/L) & $(n=3105)$ \\
\hline$\leq 1$ & $842(27 \%)$ \\
\hline$>1$ & $2263(73 \%)$ \\
\hline $\begin{array}{l}\text { Creatinine (normal range men: } 50-90 \text {, women: } \\
60-105)(\mu \mathrm{mol} / \mathrm{L})\end{array}$ & $(\mathrm{n}=5154)$ \\
\hline Within range & $2386(46 \%)$ \\
\hline Above range & $2541(49 \%)$ \\
\hline Under range & $227(4 \%)$ \\
\hline eGFR $\left(\mathrm{mL} / \mathrm{min} / 1,73 \mathrm{~m}^{2}\right)$ & $(n=4221)$ \\
\hline$\leq 60$ & $2426(57 \%)$ \\
\hline$>60$ & $1795(43 \%)$ \\
\hline $\begin{array}{l}\text { Haemoglobin (normal range women: } 7.3-9.5 \text {, men: } \\
8.3-10.5)(\mathrm{mmol} / \mathrm{L})\end{array}$ & $(\mathrm{n}=5118)$ \\
\hline Within range & $2191(43 \%)$ \\
\hline Above range & $64(1 \%)$ \\
\hline Under range & $2863(56 \%)$ \\
\hline TSH (normal range $0.35-4.0$ or $0.65-4.80)(I U / L)$ & $(\mathrm{n}=3862)$ \\
\hline Within range & $3278(85 \%)$ \\
\hline Above range & $295(8 \%)$ \\
\hline Under range & $289(7 \%)$ \\
\hline
\end{tabular}

Table 1. Patient characteristics for all patients with type 2 diabetes $\geq 80$ years included in the study. Values are displayed in absolute numbers, percentages and median (inter-quartile range). For haemoglobin and creatinine, the reference values are displayed for men and women separately. 


\begin{tabular}{|l|l|}
\hline Co-morbidities & n (\%) \\
\hline Hypertension & $3648(71 \%)$ \\
\hline Atrial fibrillation & $1990(38 \%)$ \\
\hline Congestive heart failure & $1650(32 \%)$ \\
\hline Cerebrovascular disease & $1547(30 \%)$ \\
\hline Chronic pulmonary disease & $1207(23 \%)$ \\
\hline Moderate to severe renal disease & $1079(21 \%)$ \\
\hline Non-skin malignancy & $984(19 \%)$ \\
\hline Peripheral vascular disease & $930(18 \%)$ \\
\hline Dementia & $831(16 \%)$ \\
\hline Myocardial infarction & $689(13 \%)$ \\
\hline Thyroid disorders & $524(10 \%)$ \\
\hline Depression & $455(9 \%)$ \\
\hline Peptic ulcer disease & $400(8 \%)$ \\
\hline Rheumatologic disease & $137(3 \%)$ \\
\hline Metastatic solid tumor & $124(2 \%)$ \\
\hline Moderate or severe liver disease & $41(1 \%)$ \\
\hline Schizophrenia & $10(0 \%)$ \\
\hline
\end{tabular}

Table 2. Number of patients with co-morbidities, using all available data for each individual.

We report that only $17 \%$ of included patients had an $\mathrm{HbA}_{1 \mathrm{c}}$ between $58-75 \mathrm{mmol} / \mathrm{mol}(7.5-9 \%)$, the interval generally recommended for elderly with significant comorbidities and limited life expectancy. That our patients were indeed highly comorbid is evidenced by the Charlson comorbidity score, where $94 \%$ scored 2 or more ${ }^{36}$. Of those with an $\mathrm{HbA}_{1 \mathrm{c}}<42 \mathrm{mmol} / \mathrm{mol}(<6.0 \%), 25 \%$ were treated with one or more glucose-lowering medications. These findings are in line with findings from other studies that have raised concerns about the potential overtreatment of older people with type 2 diabetes ${ }^{12,23,24,37-39}$. Among these is a large register-based study by Tseng et al. including 652,738 patients from the Veteran Health Administration. They reported that approximately $50 \%$ of patients aged 75 years or older, who were treated with insulin and/or sulphonylureas, had an $\mathrm{HbA}_{1 \mathrm{c}}<53 \mathrm{mmol} / \mathrm{mol}(<7 \%)^{12}$. Similarly, results from The Fremantle Diabetes Cohort Study, which included 367 patients over the age of 75 with type 2 diabetes showed that approximately three of five $(61 \%)$ of the patients had an $\mathrm{HbA}_{1 \mathrm{c}}<53 \mathrm{mmol} / \mathrm{mol}(<7 \%)^{37}$. As treatment needs to be individualized according to a patient's preferences and resources as well as life expectancy it is of interest that in our cohort dementia was registered as a diagnosis for $16 \%$ and non-skin malignancy for $19 \%$ of the included patients. Studies of frail patients with type 2 diabetes and limited life expectancy, such as nursing home residents, have suggested that particularly elderly with dementia are overtreated with glucose-lowering medications. Thus, in a nursing home population, $46-74 \%$ of the patients had an $\mathrm{HbA}_{1 \mathrm{c}}<53 \mathrm{mmol} / \mathrm{mol}(<7 \%)^{24,39,40}$. Although the distributions of $\mathrm{Hba}_{1 \mathrm{c}}$-values in the mentioned nursing home studies were similar to ours, cognitive and functional impairment may be more frequent in the nursing home setting. One percent $(n=70)$ of our population had hypoglycemia as the primary cause of admission. However, this is likely an underestimate of the number of patients at high risk of hypoglycemia. In older people, hypoglycemia can go undiscovered and be difficult to recognize due to unspecific symptoms ${ }^{11}$. Thus, the substantial proportion of patients, who in the context of near-normal Hbalc (i.e. below $42 \mathrm{mmol} / \mathrm{mol}(6 \%)$ ) continued treatment with a sulphonylurea $(\mathrm{n}=70)$ or insulin $(\mathrm{n}=82)$ could be considered at high risk of hypoglycemic events ${ }^{11,16}$. Thus, our study adds to the evidence suggesting that the recommendations favoring looser glycemic control in elderly, comorbid people similar to our population has not been fully adopted into clinical practice.

Our study has important strengths such as the large sample size, the high data quality from rather accurate national registers with the possibility of linking biochemical data with health record data and drug use. Nonetheless, this register-based study also has some limitations. In our study, only $34 \%$ of elderly patients with a diagnosis of type 2 diabetes were treated with glucose-lowering medications. Other studies on glycemic control in older people, including the mentioned studies of nursing home residents and larger cohort studies report a much higher proportion of patients treated with glucose-lowering medication. Thus, between $85-100 \%$ of the patients received glucose-lowering medication in other cohort studies of a general population with type 2 diabetes $^{12,23,37}$, and up to $86 \%$ were pharmacologically treated in studies investigating glycemic control in nursing home residents ${ }^{24,39,40}$. Our lower treatment prevalence is most likely due to the fact that many patients in our cohort did not meet the criteria for type 2 diabetes at the time of study. Since our study was based on a cohort identified by a hospital admission, and data analyses were limited to the time around hospital admission, we did not have information on the duration of diabetes or the glycemic control and use of antidiabetic medication over time. Access to this information could have strengthened our interpretation particularly the reason for the high proportion of patients not fulfilling the diagnostic criteria for type 2 diabetes. There is some indication that our cohort does not fully reflect the population in the capital region of Denmark. Thus, in our cohort, $54 \%$ were female, while the concurrent female proportion in the general population was $65 \%$. The reason for such relative underrepresentation of females in our cohort is unclear. Another issue is that $56 \%$ had a hemoglobin below reference level, which theoretically could lead to an underestimation of the $\mathrm{HbA}_{1 \mathrm{c}}$-values. However, as proposed by samples from another Danish population, mild to moderate anemia does not seem have significant impact on the interpretation of $\mathrm{HbA}_{1 \mathrm{c}}$-values ${ }^{41}$. 

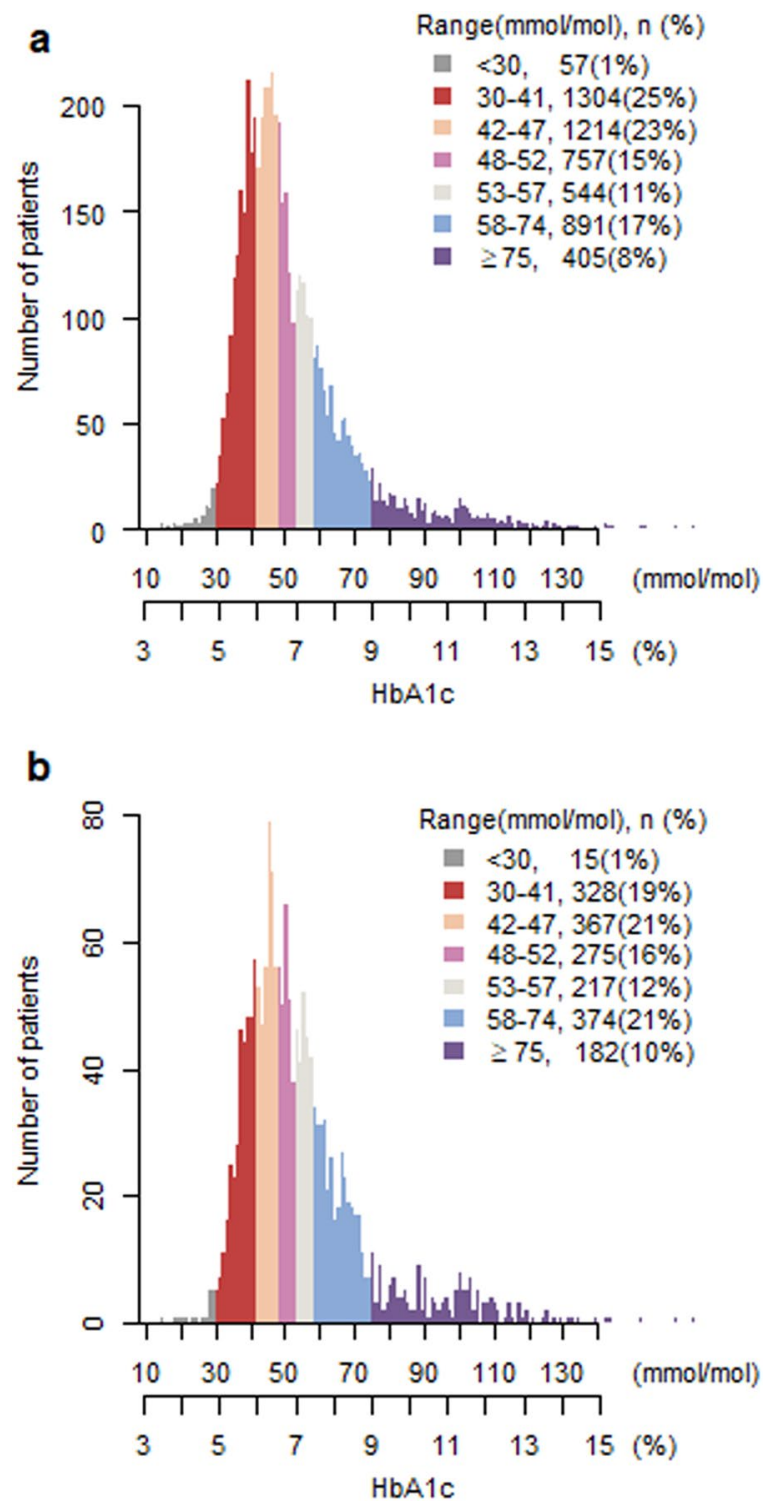

Figure 1. Distribution of individual $\mathrm{HbA}_{1 \mathrm{c}}$-values for patients with type 2 diabetes $>80$ years with and without glucose-lowering medications divided into $\mathrm{HbA}_{1 \mathrm{c}}$-categories. $\mathrm{HbA}_{1 \mathrm{c}}$-values on the $\mathrm{x}$-axis are displayed in both percentage and in $\mathrm{mmol} / \mathrm{mol}$. (a) Displays $\mathrm{HbA}_{1 \mathrm{c}}$-values for all patients $(\mathrm{n}=5172)$. (b) Displays $\mathrm{HbA}_{1 \mathrm{c}}$-values for patients treated with glucose-lowering medications $(n=1758)$.

\begin{tabular}{|c|c|c|c|c|c|c|c|c|}
\hline \multirow{2}{*}{$\begin{array}{l}\text { Number of glucose- } \\
\text { lowering medications }\end{array}$} & \multicolumn{8}{|l|}{$\mathrm{HbA}_{1 \mathrm{c}}$} \\
\hline & $<30$ & $30-41$ & $42-47$ & $48-52$ & $53-57$ & $58-74$ & $75+$ & Total \\
\hline 0 & $42(74 \%)$ & $976(75 \%)$ & $847(70 \%)$ & $482(64 \%)$ & $326(60 \%)$ & $518(58 \%)$ & $223(55 \%)$ & $3414(66 \%)$ \\
\hline 1 & $12(21 \%)$ & $279(21 \%)$ & $284(23 \%)$ & $217(29 \%)$ & $155(29 \%)$ & $250(28 \%)$ & $113(28 \%)$ & $1310(25 \%)$ \\
\hline 2 & $2(4 \%)$ & $43(3 \%)$ & $75(6 \%)$ & $50(7 \%)$ & $55(10 \%)$ & $103(12 \%)$ & $60(15 \%)$ & $388(8 \%)$ \\
\hline 3 & $0(0 \%)$ & $5(0 \%)$ & $8(1 \%)$ & $7(1 \%)$ & $7(1 \%)$ & $19(2 \%)$ & $8(2 \%)$ & $54(1 \%)$ \\
\hline 4 & $1(2 \%)$ & $1(0 \%)$ & $0(0 \%)$ & $1(0 \%)$ & $0(0 \%)$ & $2(0 \%)$ & $1(0 \%)$ & $6(0 \%)$ \\
\hline Total & $57(100 \%)$ & $1304(100 \%)$ & $1214(100 \%)$ & $757(100 \%)$ & $543(100 \%)$ & $892(100 \%)$ & $405(100 \%)$ & $5172(100 \%)$ \\
\hline
\end{tabular}

Table 3. Number of patients grouped by number of glucose-lowering medications administered at the time of hospital discharge and $\mathrm{HbA}_{1 \mathrm{c}}$-value (obtained \pm 90 days before hospital admission). $\mathrm{HbA}_{1 \mathrm{c}}$-values are divided into categories and displayed in $\mathrm{mmol} / \mathrm{mol}$.

In this hospital-based cohort consisting of more than 5000 patients, few patients $\geq 80$ years with type 2 diabetes had an $\mathrm{HbA}_{1 \mathrm{c}}$ within the limits generally recommended for this population. Many patients were not treated with glucose-lowering medications and had $\mathrm{HbA}_{1 c}$-values that could not justify a diagnosis of type 2 diabetes. Of 


\begin{tabular}{|c|c|c|c|c|c|c|c|c|}
\hline \multirow{2}{*}{$\begin{array}{l}\text { Type of glucose- } \\
\text { lowering medication }\end{array}$} & \multicolumn{8}{|l|}{$\mathrm{HbA}_{1 \mathrm{c}}$} \\
\hline & $<30$ & 30-41 & $42-47$ & 48-52 & 53-57 & 58-74 & $75+$ & Total \\
\hline Acarbose & $0(0 \%)$ & $0(0 \%)$ & $0(0 \%)$ & $0(0 \%)$ & $2(100 \%)$ & $0(0 \%)$ & $0(0 \%)$ & $2(100 \%)$ \\
\hline Basal Insulin & $1(0 \%)$ & $51(9 \%)$ & $64(11 \%)$ & $75(13 \%)$ & $79(14 \%)$ & $188(33 \%)$ & $105(19 \%)$ & $563(100 \%)$ \\
\hline Bolus Insulin & $3(2 \%)$ & $26(15 \%)$ & $23(14 \%)$ & $21(12 \%)$ & $28(17 \%)$ & $44(26 \%)$ & $24(14 \%)$ & $169(100 \%)$ \\
\hline DPP-4i & $2(1 \%)$ & $30(12 \%)$ & $56(22 \%)$ & $34(13 \%)$ & $36(14 \%)$ & $56(22 \%)$ & $38(15 \%)$ & $252(100 \%)$ \\
\hline GLP-1 RA & $0(0 \%)$ & $5(16 \%)$ & $7(23 \%)$ & $7(23 \%)$ & $1(3 \%)$ & $10(32 \%)$ & $1(3 \%)$ & $31(100 \%)$ \\
\hline Metformin & $10(1 \%)$ & $204(21 \%)$ & $254(26 \%)$ & $163(17 \%)$ & $110(11 \%)$ & $169(17 \%)$ & $75(8 \%)$ & $985(100 \%)$ \\
\hline SGLT-2i & $0(0 \%)$ & $2(12 \%)$ & $1(6 \%)$ & $2(12 \%)$ & $4(24 \%)$ & $6(35 \%)$ & $2(12 \%)$ & $17(100 \%)$ \\
\hline SU & $4(2 \%)$ & $66(26 \%)$ & $53(21 \%)$ & $40(16 \%)$ & $26(10 \%)$ & $48(19 \%)$ & $16(6 \%)$ & $253(100 \%)$ \\
\hline Total & $20(1 \%)$ & $384(17 \%)$ & $458(20 \%)$ & $342(15 \%)$ & $286(13 \%)$ & $521(23 \%)$ & $261(11 \%)$ & $2272(100 \%)$ \\
\hline
\end{tabular}

Table 4. Antidiabetic medication at the time of hospital discharge in relation to $\mathrm{HbA}_{1 \mathrm{c}}$-values (obtained \pm 90 days before hospital admission) for very old patients with type 2 diabetes. Values are displayed in absolute numbers. $\mathrm{HbA}_{1 \mathrm{c}}$-values are divided into categories and displayed in $\mathrm{mmol} / \mathrm{mol}$. Patients count more than once if administered more than one kind of antidiabetic. DPP-4i: dipeptidylpeptidase-4 inhibitor, SGLT-2i: sodiumglucose cotransporter-2 inhibitor, SU: sulfonylurea, GLP-1RA: Glucagon-like peptide-1 receptor agonist.

those treated with one or more glucose-lowering medications, quite many had either high or low $\mathrm{HbA}_{1 \mathrm{c}}$-values, suggesting under- and overtreatment, respectively. Our study supports the assumption that a diagnosis of type 2 diabetes may remit with age. Moreover, it suggests that recommendations for glycemic control in elderly patients with type 2 diabetes are not fully implemented in clinical practice.

\section{Methods}

Study cohort and data sources. The study was a retrospective cohort study using data from the Capital Region of Denmark from January 1, 2012 to May 15, 2016. We analyzed the first hospital admission for each patient, where an $\mathrm{HbA}_{1 \mathrm{c}}$ measurement in proximity to the hospital admission ( \pm 90 days) was available. On admission, patients were required to be at least 80 years of age and have a prior diagnosis of type 2 diabetes (ICD10 code DE11). Diagnoses were obtained from the regional system feeding data to The Danish National Patient Register $^{42}$. Drug utilization was obtained from The Electronic Patient Medication module, which is a database for in-hospital drug-use in the Capital Region of Denmark ${ }^{43}$. $\mathrm{HbA}_{1 \mathrm{c}}$-values, as well as biochemical status (blood lipids (cholesterol, LDL and HDL), kidney function (creatinine, eGFR), hemoglobin levels and TSH), were gathered from The Clinical Laboratory Information System ${ }^{44}$. Body Mass Index (BMI) was obtained from the medical health records. Data sources were linked using the unique and permanent Danish identification number ${ }^{45}$.

Exposure and comorbidity. Exposure to a glucose-lowering medication was defined as an active prescription of a glucose-lowering medication (Anatomical Therapeutic Chemical classification (ATC)-code A10) at the time of discharge from the hospital and with at least one administration during the hospital admission. To evaluate patient comorbidity, we used diagnoses to calculate The Charlson Comorbidity Index, which is a measure of comorbidity burden and has been shown to be correlated with life expectancy ${ }^{36}$.

Statistical methods. Data are presented using standard descriptive statistics including median and interquartile ranges. Data management was conducted using $\mathrm{R}^{46}$.

Ethics. According to the Danish “Act on Research Ethics Review of Health Research Projects” section 14 (2), retrospective register-based studies do not require ethical approval in Denmark. The study was approved by The Danish Data Protection Agency (BFH-2016-058, I-Suite nr.: 04906) and The Danish Patient Safety Authority (3-3013-1884/1/).

Compliance with ethics guidelines. This article is based on previously conducted health data and does not contain any studies with human participants or animals performed by any of the authors.

\section{Data availability}

The dataset used in this study is not available due to local law.

Received: 29 August 2019; Accepted: 27 January 2020;

Published online: 05 March 2020

\section{References}

1. American Diabetes Association. 12. Older Adults: Standards of Medical Care in Diabetes-2019. Diabetes Care 42, S139-S147 (2019).

2. International Diabetes Federation Guideline Development Group. Global guideline for type 2 diabetes. Diabetes Res. Clin. Pract. 104, 1-52 (2014).

3. McGuire, H. et al. Management of type 2 diabetes in adults: summary of updated NICE guidance. BMJ 353, i1575 (2016).

4. Handelsman, Y. et al. American Association Of Clinical Endocrinologists And American College Of Endocrinology - Clinical practice guidelines for developing a diabetes mellitus comprehensive care plan. Endocr. Pract. 21, 1-87 (2015).

5. Barnett, K. et al. Epidemiology of multimorbidity and implications for health care, research, and medical education: a cross-sectional study. Lancet Lond. Engl. 380, 37-43 (2012). 
6. Sinclair, A. et al. Diabetes mellitus in older people: position statement on behalf of the International Association of Gerontology and Geriatrics (IAGG), the European Diabetes Working Party for Older People (EDWPOP), and the International Task Force of Experts in Diabetes. J. Am. Med. Dir. Assoc. 13, 497-502 (2012).

7. American Geriatrics Society Expert Panel on Care of Older Adults with Diabetes Mellitus, Moreno, G., Mangione, C. M., Kimbro, L. \& Vaisberg, E. Guidelines abstracted from the American Geriatrics Society Guidelines for Improving the Care of Older Adults with Diabetes Mellitus: 2013 update. J. Am. Geriatr. Soc. 61, 2020-2026 (2013).

8. Action to Control Cardiovascular Risk in Diabetes Study Group et al. Effects of intensive glucose lowering in type 2 diabetes. $N$. Engl. J. Med. 358, 2545-2559 (2008).

9. Budnitz, D. S., Lovegrove, M. C., Shehab, N. \& Richards, C. L. Emergency hospitalizations for adverse drug events in older Americans. N. Engl. J. Med. 365, 2002-2012 (2011).

10. Duckworth, W. et al. Glucose control and vascular complications in veterans with type 2 diabetes. N. Engl. J. Med. 360, 129-139 (2009).

11. Bremer, J. P., Jauch-Chara, K., Hallschmid, M., Schmid, S. \& Schultes, B. Hypoglycemia unawareness in older compared with middle-aged patients with type 2 diabetes. Diabetes Care 32, 1513-1517 (2009).

12. Tseng, C.-L., Soroka, O., Maney, M., Aron, D. C. \& Pogach, L. M. Assessing potential glycemic overtreatment in persons at hypoglycemic risk. JAMA Intern. Med. 174, 259-268 (2014).

13. Abbatecola, A. M. et al. Severe hypoglycemia is associated with antidiabetic oral treatment compared with insulin analogs in nursing home patients with type 2 diabetes and dementia: results from the DIMORA study. J. Am. Med. Dir. Assoc. 16, 349.e7-12 (2015).

14. Zoungas, S. et al. Severe hypoglycemia and risks of vascular events and death. N. Engl. J. Med. 363, 1410-1418 (2010).

15. Lipska, K. J., Krumholz, H., Soones, T. \& Lee, S. J. Polypharmacy in the Aging Patient: A Review of Glycemic Control in Older Adults With Type 2 Diabetes. JAMA 315, 1034-1045 (2016)

16. Abdelhafiz, A. H., Rodríguez-Mañas, L., Morley, J. E. \& Sinclair, A. J. Hypoglycemia in older people - a less well recognized risk factor for frailty. Aging Dis. 6, 156-167 (2015).

17. Kirkman, M. S. et al. Diabetes in older adults. Diabetes Care 35, 2650-2664 (2012).

18. Boulin, M., Diaby, V. \& Tannenbaum, C. Preventing Unnecessary Costs of Drug-Induced Hypoglycemia in Older Adults with Type 2 Diabetes in the United States and Canada. PloS One 11, e0162951 (2016).

19. Currie, C. J. et al. Survival as a function of $\mathrm{HbA}(1 \mathrm{c})$ in people with type 2 diabetes: a retrospective cohort study. Lancet Lond. Engl. 375, 481-489 (2010).

20. McCoy, R. G. et al. Intensive Treatment and Severe Hypoglycemia Among Adults With Type 2 Diabetes. JAMA Intern. Med. 176, 969-978 (2016).

21. Lee, S. J. et al. The risks and benefits of implementing glycemic control guidelines in frail older adults with diabetes mellitus. J. Am. Geriatr. Soc. 59, 666-672 (2011).

22. Huang, E. S. Potential Overtreatment of Older, Complex Adults With Diabetes. JAMA 314, 1280-1281 (2015).

23. Lipska, K. J. et al. Potential overtreatment of diabetes mellitus in older adults with tight glycemic control. JAMA Intern. Med. 175, 356-362 (2015)

24. Andreassen, L. M., Sandberg, S., Kristensen, G. B. B., Sølvik, U. Ø. \& Kjome, R. L. S. Nursing home patients with diabetes: prevalence, drug treatment and glycemic control. Diabetes Res. Clin. Pract. 105, 102-109 (2014).

25. Alexander, G. C., Sehgal, N. L., Moloney, R. M. \& Stafford, R. S. National trends in treatment of type 2 diabetes mellitus, 1994-2007. Arch. Intern. Med. 168, 2088-2094 (2008).

26. Christensen, D. H., Rungby, J. \& Thomsen, R. W. Nationwide trends in glucose-lowering drug use, Denmark, 1999-2014. Clin. Epidemiol. 8, 381-387 (2016).

27. Beard, H. A., Markides, K. S., Al Ghatrif, M., Kuo, Y.-F. \& Raji, M. A. Trends in diabetes medication use and prevalence of geriatric syndromes in older Mexican Americans from 1993/1994 to 2004/2005. Ann. Pharmacother. 44, 1376-1383 (2010).

28. Lipska, K. J. et al. Trends in Drug Utilization, Glycemic Control, and Rates of Severe Hypoglycemia, 2006-2013. Diabetes Care 40, $468-475$ (2017)

29. Patrick, A. R. et al. Trends in insulin initiation and treatment intensification among patients with type 2 diabetes. J. Gen. Intern. Med. 29, 320-327 (2014).

30. Oishi, M. et al. Changes in oral antidiabetic prescriptions and improved glycemic control during the years 2002-2011 in Japan (JDDM32). J. Diabetes Investig. 5, 581-587 (2014).

31. Geller, A. I. et al. National estimates of insulin-related hypoglycemia and errors leading to emergency department visits and hospitalizations. JAMA Intern. Med. 174, 678-686 (2014).

32. Abdelhafiz, A. H., Koay, L. \& Sinclair, A. J. The Emergence of Frailty May Lead to a State of Burnt Out Type 2 Diabetes. J. Frailty. Aging 5, 162-167 (2016).

33. Abdelhafiz, A., Koay, L. \& Sinclair, A. Frailty and hypoglycaemia in older people with type 2 diabetes: Therapeutic implications. 2.

34. Taylor, R. Type 2 diabetes: etiology and reversibility. Diabetes Care 36, 1047-1055 (2013).

35. Ang, G. Y. Reversibility of diabetes mellitus: Narrative review of the evidence. World J. Diabetes 9, 127-131 (2018).

36. Charlson, M. E., Pompei, P., Ales, K. L. \& MacKenzie, C. R. A new method of classifying prognostic comorbidity in longitudinal studies: development and validation. J. Chronic Dis. 40, 373-383 (1987).

37. Bruce, D. G., Davis, W. A. \& Davis, T. M. E. Glycaemic control and mortality in older people with type 2 diabetes: The Fremantle Diabetes Study Phase II. Diabetes Obes. Metab. 20, 2852-2859 (2018).

38. McCoy, R. G., Van Houten, H. K., Ross, J. S., Montori, V. M. \& Shah, N. D. HbAlc overtesting and overtreatment among US adults with controlled type 2 diabetes, 2001-13: observational population based study. BMJ 351, h6138 (2015).

39. Bo, M. et al. Prevalence, Clinical Correlates, and Use of Glucose-Lowering Drugs among Older Patients with Type 2 Diabetes Living in Long-Term Care Facilities. J. Diabetes Res. 2015, 174316 (2015).

40. Basso, A., Peruzzi, P., Carollo, M. C., Improta, G. \& Fedeli, U. Assessment of glycemic control among diabetic residents in nursing homes. Diabetes Res. Clin. Pract. 96, e80-83 (2012).

41. Borg, R. et al. Interpretation of HbAlc in primary care and potential influence of anaemia and chronic kidney disease: an analysis from the Copenhagen Primary Care Laboratory (CopLab) Database. Diabet. Med. J. Br. Diabet. Assoc. 35, 1700-1706 (2018).

42. Lynge, E., Sandegaard, J. L. \& Rebolj, M. The Danish National Patient Register. Scand. J. Public Health 39, 30-33 (2011).

43. Jensen, T. B. et al. Content and validation of the Electronic Patient Medication module (EPM) - the administrative in-hospital drug use database in the Capital Region of Denmark. Scand. J. Public Health 140349481876005 https://doi.org/10.1177/1403494818760050 (2018).

44. Grann, Erichsen, R., Nielsen, Frøslev \& Thomsen, R. Existing data sources for clinical epidemiology: The clinical laboratory information system (LABKA) research database at Aarhus University, Denmark. Clin. Epidemiol. 133 https://doi.org/10.2147/CLEP. S17901 (2011).

45. Schmidt, M., Pedersen, L. \& Sørensen, H. T. The Danish Civil Registration System as a tool in epidemiology. Eur. J. Epidemiol. 29, 541-549 (2014)

46. Team, R. C. R: A Language and Environment for Statistical Computing. (2018). 


\section{Acknowledgements}

The study was funded by the Department of Clinical Pharmacology, Bispebjerg and Frederiksberg Hospital, University of Copenhagen.

\section{Author contributions}

D.R.G. and S.V. contributed to drafting of the manuscript and data analyses. T.S.P., T.B.J. and R.C. contributed to study design and data analyses. E.J.S. and M.C. designed the study and contributed to data analyses and manuscript drafting. All authors edited and approved the manuscript.

\section{Competing interests}

The authors declare no competing interests.

\section{Additional information}

Correspondence and requests for materials should be addressed to M.B.C.

Reprints and permissions information is available at www.nature.com/reprints.

Publisher's note Springer Nature remains neutral with regard to jurisdictional claims in published maps and institutional affiliations.

(c) (i) Open Access This article is licensed under a Creative Commons Attribution 4.0 International License, which permits use, sharing, adaptation, distribution and reproduction in any medium or format, as long as you give appropriate credit to the original author(s) and the source, provide a link to the Creative Commons license, and indicate if changes were made. The images or other third party material in this article are included in the article's Creative Commons license, unless indicated otherwise in a credit line to the material. If material is not included in the article's Creative Commons license and your intended use is not permitted by statutory regulation or exceeds the permitted use, you will need to obtain permission directly from the copyright holder. To view a copy of this license, visit http://creativecommons.org/licenses/by/4.0/.

(C) The Author(s) 2020 